\title{
Evaluation of the Chemical Vacuum Effect in Decarburization Treatment by Argon-injected Steel under Normal Atmosphere
}

\author{
Takeo INOMOTO, ${ }^{1 / *}$ Michitaka MATSUO ${ }^{2)}$ and Masataka YANO ${ }^{3)}$ \\ 1) Process Research Laboratories Nippon Steel \& Sumitomo Metal Corporation, 16-1 Sunayama, Kamisu-shi, Ibaraki, $314-0255$ \\ Japan. $\quad 2$ 2) Formerly Process Technology Research Laboratories Nippon Steel Corporation. Now at The Japan Research \\ and Development Center for Metals, 1-5-11 Nishi-Shinbashi, Minato-ku, Tokyo, 105-0003 Japan. 3) Formerly Process \\ Technology Research Laboratories Nippon Steel Corporation. Professor Emeritus, Aichi University of Technology, Now at 104 \\ Nakagou-aza, Ushikawa-chou, Toyohashi-Shi, Aichi, 440-0016 Japan.
}

(Received on August 21, 2014; accepted on January 4, 2015)

\begin{abstract}
For the mass production of ultra-low-carbon steel, application of the chemical vacuum method was examined in depth. In the present study, based on the results of 600-kg-scale experiments and theoretical analysis of them, the possibility of innovative creation producing ultra-low-carbon products without using a vacuum degasser was obtained.

To confirm the effect, a 60-t-scale AOD plant test was carried out. As a result, by using the chemical vacuum effect, the carbon content is reduced to $9 \mathrm{ppm}$ in normal steel because of its much higher CO partial pressure than that of stainless steel.

The results of the examination show that, theoretically, the reaction rate can be further enhanced. However, it is necessary to construct a dispersion condition in a large-scale metal vessel with small argon bubbles because applying the current technique of small bubble production cannot produce a sufficiently high argon injection flow rate.

For the construction of an innovative secondary refining process in the future steelmaking process, the gas dispersion technique is strongly preferred.
\end{abstract}

KEY WORDS: steelmaking; reaction rate; decarburization; gas injection; AOD; IF steel.

\section{Introduction}

The chemical vacuum degassing phenomenon is employed in several laboratorial experiments to control the mass transfer coefficient in the gas boundary layer of the gas-metal interface. For the kinetic study of decarburization, the inert gas blowing method is also popular and distinguished works have been undertaken. ${ }^{1)}$ Using this phenomenon, the degassing process by argon gas injection (AOD method) is established and has advanced thanks to the many kinds of works. ${ }^{2)}$ As well as the VOD process, the AOD process is mainly applied in decarburization in stainless steel production, because the high alloy content of chromium causes a reduction in the activity of carbon and oxygen. Therefore, to obtain the required carbon content material, decarburization processes by oxygen supply under decreased CO partial pressure were established.

According to the demand for low-carbon stainless steel, the operation technology has advanced. In recent operation, the carbon content can be reduced to less than $50 \mathrm{ppm}$ using the AOD process without a vacuum facility. For the production of low-carbon stainless steel, the optimum argon injection condition is selected.

\footnotetext{
* Corresponding author: E-mail: inomoto.4m3.takeo@jp.nssmc.com DOI: http://dx.doi.org/10.2355/isijinternational.55.723
}

Besides, in the commercial normal steel plant, ultra-lowcarbon steel was being produced by Q-BOP reactor $(240 \mathrm{t} / \mathrm{ch}$ ) during early 1990s. In this process, at the end of normal decarburization treatment, a large amount of inert gas was injected via bottom tuyeres. As a result of this operation, the carbon content could be reduced to $65 \mathrm{ppm}^{3}{ }^{3}$

In addition, to obtain ultra-low-carbon steel using argon injection under normal pressure, Kouroki et al. performed a 30-kg-scale experiment with multi-hole argon bubbling, which showed that the decarburization rate was promoted by the bubble dispersion effect, and the carbon content reached 3 ppm. ${ }^{4}$ Furthermore, Komatani et al. tried bottom and side combined argon injection tests using a 10-t-scale converter. As a result, 18 ppm carbon steel was obtained after 12 -min treatment. ${ }^{5)}$

From this description, it might possible to produce not only ultra-low-carbon stainless steel but also ultra-low-carbon normal steel in a large-scale reactor using the chemical vacuum method. However, the utility cost of argon is quite high and the price of a normal-steel product is quite lower than a stainless-steel product. On the other hand, the amount of heat and the scale of production of a current normal steel plant are much greater than those of a stainless steel plant. So, to consider the application of an AOD-like process to a current massive steelmaking factory, deliberative reflection, in comparison with the usual degassing process, is necessary. 
In the present study, using a $600-\mathrm{kg}$-scale induction furnace and a 60-t-scale commercial AOD equipment, the reaction rate in normal and high-alloy steel was examined, and the potential and future applicability were discussed.

\section{600-kg-scale Experiments}

The 600-kg-scale experiments were carried out using two kinds of steel ( $17 \mathrm{wt} \% \mathrm{Cr}$-steel and normal steel). The inner diameter of the magnesia crucible was $380 \mathrm{~mm}$, so the metal depth came to $750 \mathrm{~mm}$. At the beginning of the experiment, the initial carbon content was controlled to the target range by the addition of carbon and sample analysis. After 30 minutes of holding, the first sample was taken and argon gas injection was started via a bottom porous plug. In every experiment, no carbon content change occurred during the holding time. This fact indicates that carbon loss at the surface area is negligible and that the decarburization reaction dominantly occurs by $\mathrm{CO}$ gas adsorption into the argon bubbles under this experimental condition (normal pressure: 760 Torr, $1823-1873 \mathrm{~K}$ ).

In Fig. 1, the experimental results obtained with normal steel are shown. Under a high-oxygen-content condition $(\bullet$, -), the carbon reduction rate is higher than the reaction rate under a middle-oxygen-content condition $(\triangle)$. In both conditions, oxygen content is enough higher than the carbon content, and carbon mass transfer coefficient at the metal boundary layer surrounding bubbles can be considered same value. So, mass transfer rate of oxygen and carbon doesn't affect reaction rate. Besides Harashima et al. showed about the adsorption effect of oxygen which can obstruct chemical reaction rate of decarburization reaction (oxygen content $>$ $200 \mathrm{ppm}){ }^{6}$ ) regarding this effect, chemical reaction rate at the gas-metal interface can't be promoted with high oxygen content condition. Therefore the promotion of reaction rate in the high oxygen condition can be realized by the promotion of the mass transfer of $\mathrm{CO}$ gas into unsaturated Ar bubbles because of high $\mathrm{CO}$ partial pressure in the metal.

Figure 2 shows the results obtained with the $17 \mathrm{wt} \% \mathrm{Cr}-$ steel, which shows a much slower reaction rate than that of normal steel. This degradation of reaction rate in the high $\mathrm{Cr}$ steel can be also considered by decreasing of the $\mathrm{CO}$ partial pressure as described follows.

Generally, under high CO partial pressure of the metal, rising argon bubbles can absorb a large amount of $\mathrm{CO}$ gas. To consider this concept, based on Ohno's AOD reaction

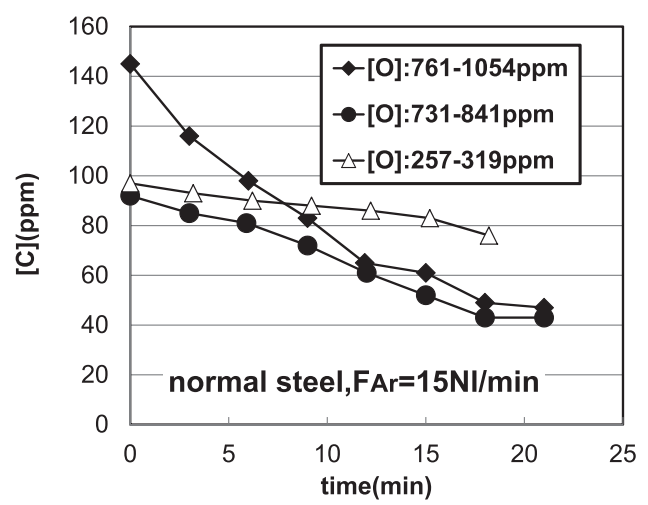

Fig. 1. Change in the carbon content (normal steel). model, ${ }^{2)}$ the reaction rate was estimated by the average saturation rate $\left(\eta_{\mathrm{Ar}}\right)$. This estimation method is illustrated in Fig. 3. Injected argon bubbles rose up in the metal with the absorption of $\mathrm{CO}$ gas generated from the $\underline{\mathrm{C}}$ and $\underline{\mathrm{O}}$. The $\mathrm{CO}$ partial pressure in the metal changed during the experiment by the reduction in $\mathrm{C}$ content; in addition, the $\mathrm{O}$ level did not change significantly. In this estimation, based on the initial carbon content and average oxygen content in each experiment, the reduction rate of the carbon content was calculated at the fixed $\eta_{\text {Ar }}$ value.

Using the above method, the calculated results are shown in Figs. 4, 5, and 6. The results show that the injected bubbles absorbed $\mathrm{CO}$ gas to about half the saturation state. To obtain higher argon efficiency, reducing the bubble size or extending the residential time of bubbles is required. However, if the mass transfer rate of $\mathrm{CO}$ gas in the inner bubble layer could be increased much high, and closed to the saturation state, it is impossible to promote the reaction rate more than double.

Therefore, to promote the reaction rate, both optimum argon gas flow rate and optimum increase in the $\eta_{\text {Ar }}$ value, according to the process condition, are required.

\section{60-t-scale Plant Experiments}

As described above, the partial pressure of $\mathrm{CO}$ gas in nor-

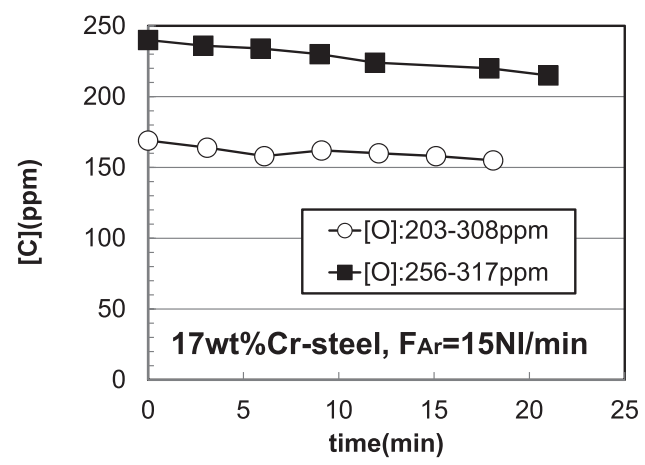

Fig. 2. Change in the carbon content $(17 \mathrm{wt} \% \mathrm{Cr}$-steel $)$.

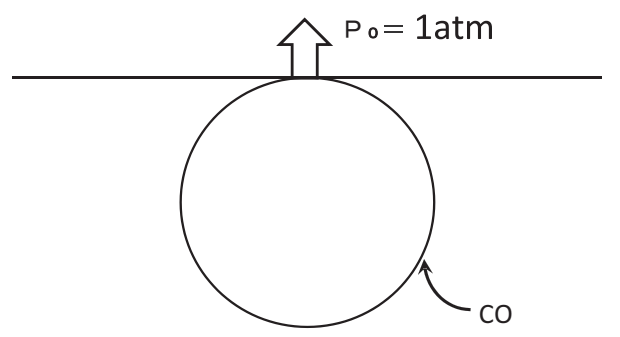

$$
\begin{aligned}
& \mathrm{Pco}^{\text {in the bubble }}=\mathrm{Po}_{\mathrm{o}} \cdot \mathrm{V}_{\mathrm{co}} /\left(\mathrm{V} \mathrm{Co}+\mathrm{VAr}_{\mathrm{A}}\right) \\
& \mathrm{Pco} \text { in the metal } \\
& =\mathrm{ac} \cdot \mathrm{ao} \cdot \mathrm{K} \\
& =\mathrm{fc} \cdot \mathrm{fo} \cdot[\mathrm{C}][\mathrm{O}](1160 / \mathrm{T})+2.003 \\
& \text { normal steel:fc } \fallingdotseq 1, \mathrm{fo} \fallingdotseq 1 \\
& 17 \mathrm{wt} \% \mathrm{Cr}-\mathrm{steel}: \mathrm{fc}=0.41, \mathrm{fo}=0.19
\end{aligned}
$$

$$
\begin{aligned}
& \text { Saturated condition } \eta \mathrm{Ar}=1.0 \\
& \mathrm{P} \mathrm{co}^{\text {in the bubble }}=\eta \mathrm{Ar} \cdot \mathrm{P} \mathrm{co}^{\text {in the metal }}
\end{aligned}
$$

Fig. 3. Illustration of CO gas absorption into rising argon bubbles. 


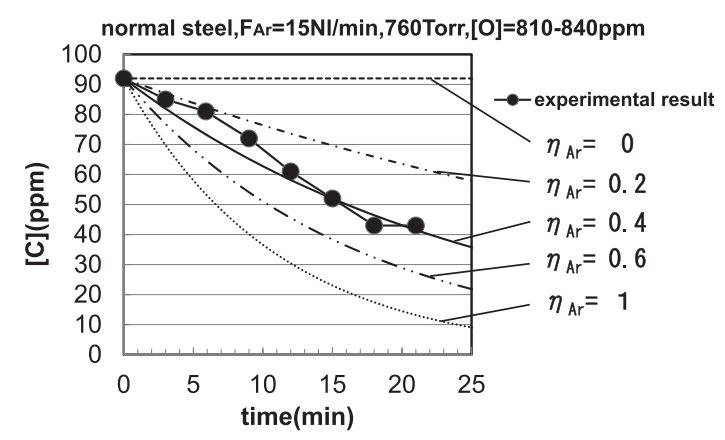

Fig. 4. Reaction rate estimation (normal steel, high oxygen level).

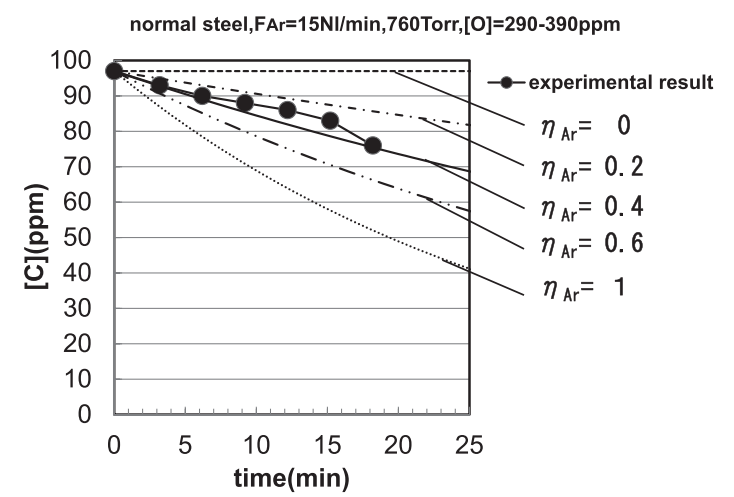

Fig. 5. Reaction rate estimation (normal steel, middling oxygen level).

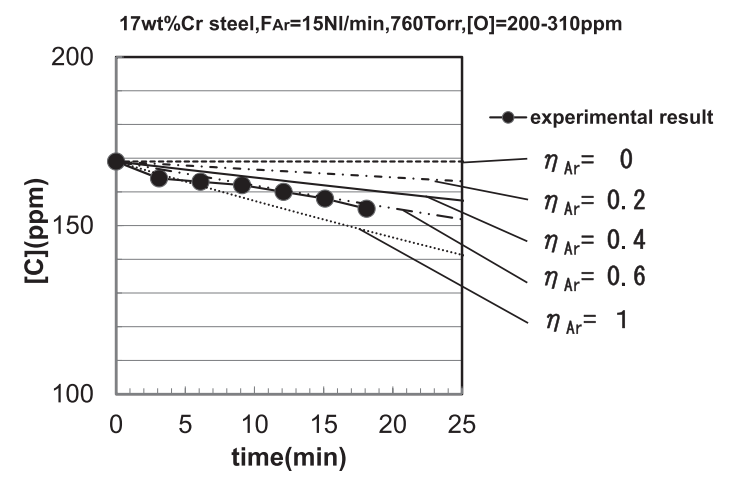

Fig. 6. Reaction rate estimation ( $17 \mathrm{wt} \% \mathrm{Cr}$-steel, middling oxygen level).

mal carbon is much higher than that in stainless steel. As shown in the scheme of AOD (Fig. 7), the side-blowing method can achieve a longer length of the bubbling zone than the bottom-injection method (Q-BOP).

In this experiment, three kinds of steel grade were used to estimate the influence of $\mathrm{CO}$ partial pressure. The steel grades and their activity coefficients of carbon and oxygen are listed in Table 1. ${ }^{7}$ According the equation in Fig. 3, invar metal has the highest CO partial pressure among the three kinds of steel grade.

Five tuyeres were used, and at the beginning of the decarburization treatment of high-carbon-content steel, about 75 vol\% of oxygen was injected with argon gas (total 3000 $4000 \mathrm{Nm}^{3} / \mathrm{h}$ ) to promote the reaction rate in the high-carbon range. And at the end of treatment, oxygen supply was reduced to less than $10 \mathrm{vol} \%$ of the argon gas flow rate so as to maintain the necessary oxygen content, and the argon gas flow rate was increased up to about $2000 \mathrm{Nm}^{3} / \mathrm{h}$.

Each experimental result is shown in Figs. 8, 9, and 10

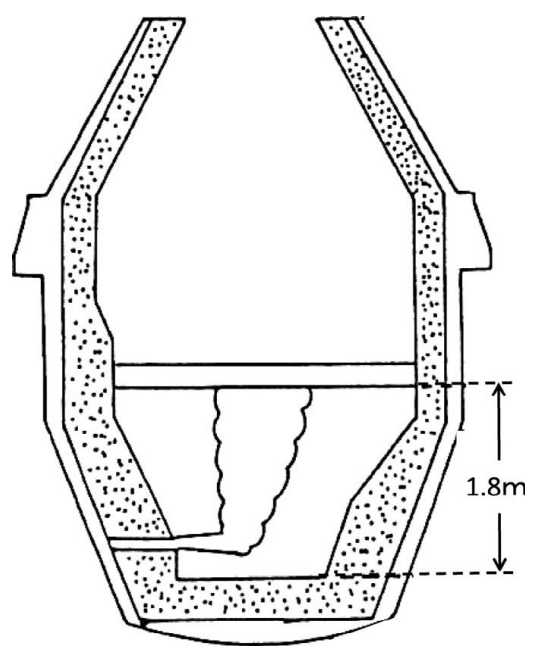

Fig. 7. Scheme of the AOD equipment.

Table 1. Composition and activity coefficient of each condition (AOD experiment).

\begin{tabular}{cccccc}
\hline & {$[\mathrm{wt} \% \mathrm{Cr}]$} & {$[\mathrm{wt} \% \mathrm{Ni}]$} & $\mathrm{fc}$ & fo & $\mathrm{fc} \times$ fo \\
\hline SUS304 grage & $15-18$ & 10 & 0.68 & 0.24 & 0.16 \\
normal steel & $<0.4$ & $<0.5$ & 1 & 1 & 1 \\
invar metal & $<0.2$ & 33 & 2.6 & 1.6 & 4.2 \\
\hline
\end{tabular}

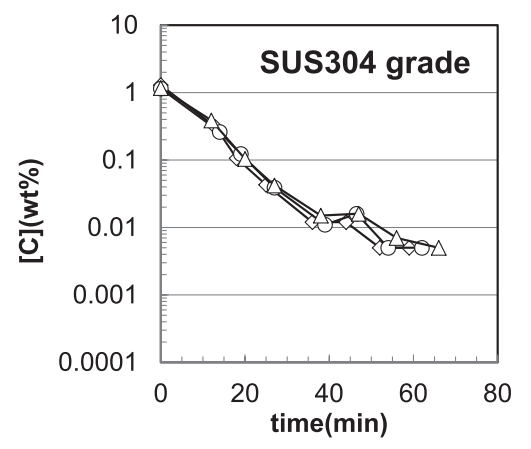

Fig. 8. Experimental result with SUS 304-grade steel.

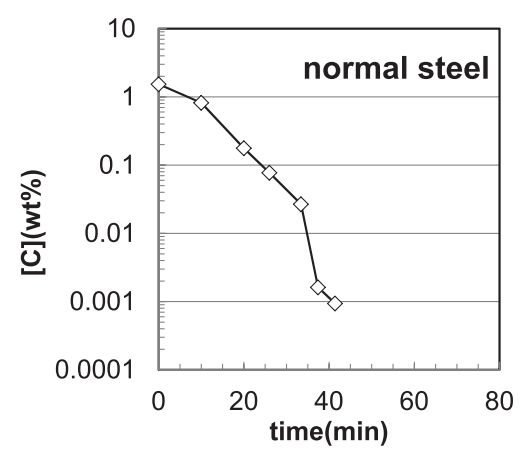

Fig. 9. Experimental result with normal steel.

respectively. As expected, in the case of normal steel and invar metal, the decarburization rate is quite higher than that of the SUS304-grade steel. A carbon content of 9 ppm (in normal steel) and $7 \mathrm{ppm}$ (in invar metal) at the end point is obtained.

From the results of these plant experiments, the $\eta_{\text {Ar }}$ value was obtained during the argon gas chemical vacuum treat- 


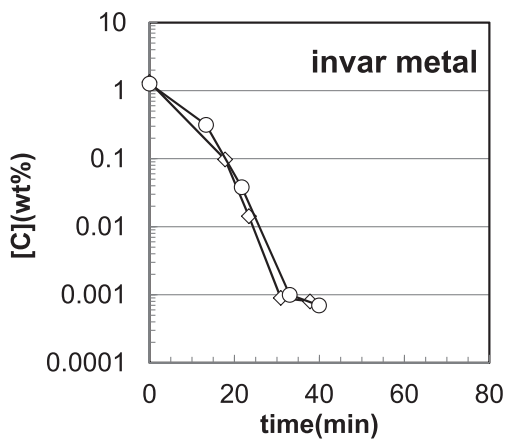

Fig. 10. Experimental result with invar metal.

Table 2. Experimental result of $\eta_{\mathrm{Ar}}$ in the late period.

\begin{tabular}{ccc}
\hline SUS304 grade & normal steel & invar metal \\
\hline$\eta_{\mathrm{Ar}}=0.47-0.58$ & $\eta_{\mathrm{Ar}}=0.24$ & $\eta_{\mathrm{Ar}}=0.13-0.15$ \\
\hline
\end{tabular}

ments, as listed in Table 2. As shown in Table 2, in the case

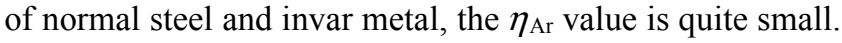

In the $600-\mathrm{kg}$-scale experiments which described above, the obtained $\eta_{\text {Ar }}$ value using normal steel were around 0.5 (normal steel), while the $\eta_{\text {Ar value which obtained } 60 t-s c a l e}$ plant test was half of them. This fact suggests that the size of argon bubbles which produced near the 60t-AOD tuyeres is larger than the size of bubbles by $600-\mathrm{kg}$-scale experiments, and consequently, the large bubbles absorb CO gas inadequately during rising up in the metal.

Besides, CO partial pressure of the SUS304 grade is much lower than the normal steel's CO partial pressure, so, high $\eta_{\text {Ar }}$ value is obtained even small quantity of $\mathrm{CO}$ absorption. Therefore in the same operating condition, the experiment of SUS304 grade shows higher value of $\eta_{\text {Ar }}$ than the experiment of normal steel. On the other hand, in the case of invar metal, $\mathrm{CO}$ partial pressure is quite high, so the lowest $\eta_{\text {Ar }}$ value is obtained in the three experimental conditions.

\section{Discussion}

The result of present experiments shows the possibility of technical innovation in the secondary refining process, applying the highly efficient chemical vacuum degasser to future factories that produce ultra-low-carbon steel of normal steel grade. From this point of view, promotion of decarburization efficiency by increasing the $\eta_{\text {Ar }}$ value is necessary.

Considering this, a special technique to produce small argon bubbles is required. Several studies to obtain small bubbles have been reported, using an ultrasonic technique, ${ }^{8)}$ multiple pores on a vertical wall, ${ }^{9)}$ mercury experiment with a rotating cup, ${ }^{10}$ molten steel experiment with a wide porous plug, ${ }^{11)}$ plant test in the tundish pathway, ${ }^{12)}$ and argon bubble dispersion and reaction promotion effect by electromagnetic stirring. ${ }^{13)}$ However, these methods can reduce the bubble size only in a small area or under the late low-argonflow condition. The results of the experimental and theoretical studies on the gas holdup phenomenon ${ }^{14-16)}$ show that at hard injection of argon gas into molten metal, initial bubbles immediately split into groups of similar-sized bubbles, and considering this knowledge, the bubble-rising velocity is more than $600 \mathrm{~mm} / \mathrm{sec}$ and the average diameter is estimated to be larger than $70 \mathrm{~mm}$.

Based on the 60t-AOD experimental result using normal steel, argon consumption during secondary refining range (after BOF, initial [C] $0.03 \mathrm{wt} \%$ to $10 \mathrm{ppm}$ ) is $6-7 \mathrm{Nm}^{3} / \mathrm{t}$. From the view point that the commutation form regular vacuum degassing process to normal pressure argon injection process, because of the utility cost estimation, deduction of argon consumption (lower than $2 \mathrm{Nm}^{3} / \mathrm{t}$ ) which indicated increasing of $\eta_{\text {Ar }}$ value (more than 0.7 ) is required. Therefore total bubble surface area should be increased more than three times area of present plant test by decreasing bubble diameter less than $20 \mathrm{~mm}$.

Considering the current industrial condition, to supply necessary argon flow rate and to avoid fatal refractory damage, gas injection with jet core method is necessary, so some technological breakthrough which enable to control bubble size at the jet/bubble conversion area would be desired.

\section{Conclusion}

The possibility of the chemical vacuum process for ultralow-carbon steel production in normal steel production was considered based on the result of examination using a 600$\mathrm{kg}$-scale induction furnace and a 60-t-scale AOD. The experimental results and theoretical analysis indicate the possibility of a highly effective degassing process without a vacuum degasser, assuming the argon gas dispersion technique to be established.

However, considering former understanding of bubble behavior and the current technology of making small bubbles, it is difficult to construct a new process exceeding the degassing ability of the recent secondary steelmaking process.

The result of the current work strongly expresses the importance of a new technology that creates the dispersion of small bubbles in a large-scale molten metal vessel for an innovative steelmaking process.

\section{REFERENCES}

1) For Examlple, H. Yetao, T. Sawada, M. Kato and M. Sano: Tetsu-toHagané, 77 (1991), 377.

2) For Examlple, T. Ohno and T. Nishida: Tetsu-to-Hagané, 63 (1977), 2094.

3) P. Chapellier, A. Leclercq, P. Ravaux and B. Sarter: Proc. 3rd IOSC, Tne Institute of Metals, London, (1990), 278.

4) S. Kouroki and T. Hirata: CAMP-ISIJ, 4 (1991), 230.

5) M. Komatani, S. Inoue, I. Kikuchi and A. Inoue: CAMP-ISIJ, 7 (1994), 231.

6) K. Harashima, S. Mizoguchi, M. Matsuo and A. Kiyose: ISIJ Int., 32 (1992), 111.

7) T. Inomoto, M. Matsuo and M.Yano: CAMP-ISIJ, 16 (2003), 1067.

8) M. Kawakami, S. Douwaki, T. Hiroe and K. Ito: Tetsu-to-Hagené, 78 (1992), 745 .

9) K. Okano, M. Kuwabara and K. Yan: CAMP-ISIJ, 17 (2004), 826.

10) S. Yokoya, S. Takagi, M. Iguchi and S. Hara: CAMP-ISIJ, 14 (2001), 785.

11) H. Kuwatori, K. Okohira and T. Murata: Tetsu-to-Hagené, 73 (1987), S958.

12) K. Takase, K. Misawa, K. Amada, M. Amano, N. Konno, A. Uehara and H. Yamamura: CAMP-ISIJ, 10 (1997), 138.

13) K. Harashima, T. Inomoto, M. Matsuo and M. Yano: CAMP-ISIJ, 5 (1992), 272.

14) T. Fujii and I. Muchi: Tetsu-to-Hagené, 56 (1970), 558.

15) M. Sano and K. Mori: Tetsu-to-Hagené, 64 (1978), 1714.

16) M. Iguchi, Z. Morita, H. Tokunaga, H. Tatemichi, Y. Sakamoto and S. Takagi: Tetsu-to-Hagené, 79 (1993), 561.

17) M. Hino and K. Ito: Termodynamic Data for Steelmaking, Tohoku University Press, Sendai, (2010). 